of the femoral neck by consolidated callus, or perhaps to a tendency for the patient to fall away from the side of the previous injury.

Conclusion. If a patient's symptoms warrant removal of the implant used to fix a hip fracture, this can be done without an increased risk of refracture of that hip, provided there is radiological evidence of union of the fracture.

I would like to thank the consultant orthopaedic surgeons at Northwick Park Hospital for permission to report their patients; to Dr Jonathan Reeve of the Bone Disease Research Group for helping with the preparation of this manuscript and the Medical Research Council for their financial support.
No benefits in any form have been received or will be received from a commercial party related directly or indirectly to the subject of this article.

\section{REFERENCES}

Boyce WJ, Vessey MP. Rising incidence of fracture of the proximal femur. Lancet 1985; i:150-1.

Finsen V, Benum P. Refracture of the hip rare after removal of fixation device. Acta Orthop Scand 1986; 57:434-5.

Melton LJ III, Ilstrup DM, Beckenbaugh RD, Riggs BL. Hip fracture recurrence: a population-based study. Clin Orthop 1982; 167:1318

Stewart IM. Fractures of neck of femur: incidence and implications. Br Med J 1955; i :698-701.

\title{
SOURCE OF THE CEMENT WITHIN THE CHARNLEY HIP
}

\author{
G. H. ISAAC, B. M. WROBLEWSKI, J. R. ATKINSON， D. DOWSON
}

We have already reported the damaging effects of intraarticular acrylic cement on both the femoral head and the acetabular cup (Isaac et al 1986). In that series of 59 sockets $51(86 \%)$ showed damage, and intra-articular cement was found in $29(49 \%)$. The abrasive constituent has been isolated, and the implications of this damage discussed (Isaac et al 1987). It is of practical importance to identify the source of the cement in order to minimise its effects on socket wear and loosening. Some of the free cement particles are no doubt the result of the surgical technique, but others are due to the design of the prosthesis; the acetabular component would appear to be the more likely source because of its proximity, exposed area (unless covered by a flange) and the effects of impingement of the neck of the stem against any protruding cement.

An opportunity to study this problem presented itself when a collection of Charnley press-fit sockets, obtained at post-mortem, became available. In the evolution of the Charnley low friction arthroplasty (LFA) there was a time when a series of uncemented metalbacked high density polyethylene (HDP) press-fit sockets (Fig. la) were used with a cemented stem. After reaming the acetabulum the press-fit socket was inserted with the central HDP spigot engaging into the pilot hole of the acetabulum (Fig. 1b). No attempt was made to restrict

G. H. Isaac, PhD, Biomechanical Engineer

B. M. Wroblewski, FRCS, Consultant Orthopaedic Surgeon

Centre for Hip Surgery, Wrightington Hospital, Appley Bridge, near Wigan, Lancashire WN6 9EP, England.

J. R. Atkinson, DPhil, Senior Lecturer, Department of Metallurgy

D. Dowson, FRS, Head of the Department of Mechanical Engineering University of Leeds, Leeds LS2 9JT, England.

Correspondence to Dr G. H. Isaac.

C 1990 British Editorial Society of Bone and Joint Surgery $0301-620 X / 90 / 1$ R $50 \$ 2.00$

J Bone Joint Surg [Br] 1990; 72-B : 149-50 rotation of the socket around its central axis, in the hope that this freedom would reduce the likelihood of unidirectional wear, thus avoiding impingement and loosening. Between November 1962 and December 1965, 336 such sockets were inserted, though their use was subsequently abandoned. This present study reviews those press-fit sockets which have become available. It sought to determine the extent of cement damage and to identify the source of the intra-articular cement; it was not concerned with the reasons that the design failed.

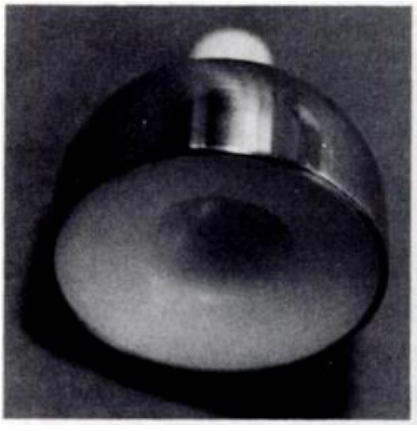

Fig. 1a

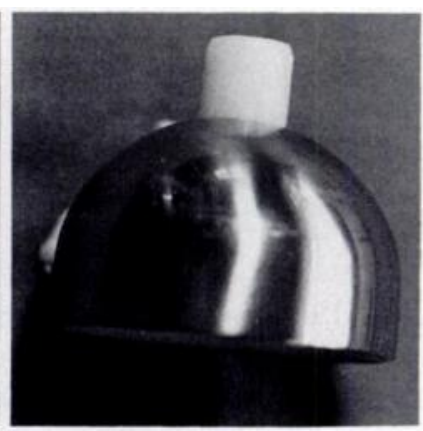

Fig. Ib
Material and method. Of the post-mortem specimens bequeathed to the late Sir John Charnley, 15 were of the press-fit variety. They were excised intact with the surrounding tissues and stored in formalin until examination. The socket bore was examined visually to see if it contained acrylic cement. Then, using dental casting cement, casts of the socket bore were made and dimensional changes were measured using the shadowgraph technique.

Results. Of the 15 sockets, 10 were from women and five from men. Eight were from the right hip, seven from the left. The mean age of the patients at the time of the arthroplasty was 69 years (range 48 to 79 ) and their mean 
weight was $68 \mathrm{~kg}$ (range 43 to 86). The mean follow-up was 10.7 years (range 6.7 to 17).

The high and the low wear areas were still visible, but the machining marks could not always be seen, suggesting that at some stage after the operation the socket did in fact spin on its central axis. No cement was found in any of the sockets, but seven showed areas which were consistent with cement having been present. These were, however, small and limited to one or two areas per socket. Seven sockets showed rim wear and eight were slightly discoloured.

The mean penetration of the sockets was $1.13 \mathrm{~mm}$ and the mean penetration rate was $0.1 \mathrm{~mm}$ per year (range 0.02 to $0.17 \mathrm{~mm}$ ). This penetration rate was within the range previously reported (Table I) but lower than in recent studies where the prostheses were obtained at revision.

Conclusion. When compared with the gross damage previously observed in cemented sockets, the absence of cement within the press-fit socket in eight cases and only minimal damage in the other seven suggests that the source of the acrylic cement (other than any resulting from the surgical technique) is probably from the acetabular side. If so, then improvement in the surgical technique and the use of flanged sockets should reduce the likelihood of cement ingress and the resulting cement damage.

No benefits in any form have been received or will be received from a commercial party related directly or indirectly to the subject of this article.
Table I. Penetration rate into the high density polyethylene socket in the Charnley hip from various studies

\begin{tabular}{|c|c|c|c|c|}
\hline & Cases & $\begin{array}{l}\text { Mean } \\
\text { follow-up (yr) }\end{array}$ & $\begin{array}{l}\text { Mean } \\
\text { age (yr) }\end{array}$ & $\begin{array}{l}\text { Penetration } \\
\text { rate } \mathbf{m m} / \mathbf{y r}\end{array}$ \\
\hline $\begin{array}{l}\text { Griffith et al } \\
(1978)^{*}\end{array}$ & 491 & 8.3 & 62 & 0.07 \\
\hline $\begin{array}{l}\text { Isaac et al } \\
(1986) \dagger\end{array}$ & 52 & 9.1 & 56 & 0.22 \\
\hline $\begin{array}{l}\text { Wroblewski } \\
(1986)^{*}\end{array}$ & 103 & 16.6 & 53 & 0.096 \\
\hline Present series $\dagger$ & 15 & 10.7 & 69 & 0.1 \\
\hline
\end{tabular}

* radiographic technique † shadow graphic technique

\section{REFERENCES}

Griffith MJ, Seidenstein MK, Williams D, Charnley J. Socket wear in Charnley low friction arthroplasty of the hip. Clin Orthop 1978; 137:37-47.

Isaac GH, Atkinson JR, Dowson D, Wroblewski BM. The role of cement in the long term performance and premature failure of Charnley low friction arthroplasties. Eng Med 1986; 15:19-22.

Isaac GH, Atkinson JR, Dowson D, Kennedy PD, Smith MR. The causes of femoral head roughening in explanted Charnley hip prostheses. Eng Med 1987; 16:167-73.

Issac GH, Atkinson JR, Dowson D, Wroblewski BM. The role played by the acrylic cement in determining the penetration rate of the femoral head in the P.E. sockets of the Charnley hip prostheses. In: Willert $\mathrm{H}$, Buchhorn G, Eyerer P, eds. Ultra-high molecular weight polyethylene as a biomaterial in orthopaedic surgery. Berne: H. Huber, 1989 (in press).

Wroblewski BM. 15-21-year results of the Charnley low-friction arthroplasty. Clin Orthop 1986; $211: 30-5$.

\title{
SNAPPING HIP - AN UNUSUAL CAUSE
}

\author{
K. SATKU， J. CHIA， V.P. KUMAR
}

We report three patients who developed a snapping hip after operations for anterolateral instability of the knee. Two varieties of snapping hip are recognised : an internal snap related to the iliopsoas tendon where it crosses the hip, and an external snap thought to be due to the iliotibial band or the gluteus maximus tendon slipping over the greater trochanter (Schaberg, Harper and Allen 1984). The condition usually becomes manifest during or after adolescence. Our three patients developed a snapping hip of the 'external' variety following surgery

K. Satku, M Med, FRCS, Senior Lecturer and Consultant J. Chia, MB BS, Orthopaedic Resident

V. P. Kumar, FRCS (Glas), FRCS (Ed), Senior Lecturer and Consultant

Department of Orthopaedic Surgery, National University Hospital, 5 Lower Kent Ridge Road, Singapore 0511, Republic of Singapore.

Correspondence to Mr K. Satku.

(C) 1990 British Editorial Society of Bone and Joint Surgery 0301-620X/90/1R41 \$2.00

J Bone Joint Surg [Br] 1990; 72-B: 150-1. for anterolateral instability of the ipsilateral knee. They were seen over a period of 10 years during which 126 patients had similar operations without this complication.

Case reports. Case 1 was a man aged 26 years, case 2 a man aged 25 and case 3 a woman aged 20 . Cases 1 and 3 had anterolateral instability that significantly disabled them during their normal daily activities. Case 2 was able to cope with normal activities but was unable to return to his pre-injury employment as a physical instructor in the armed forces. In all three the anterior cruciate ligament was reconstructed using a free patellar tendon graft (Paterson and Trickey 1986) combined with an extra-articular MacIntosh type of tenodesis (Trickey 1979). The resulting defect in the iliotibial band was closed.

Case 1 developed a snapping hip two years after operation, when he had returned to recreational sport; later he also had pain over the greater trochanter when 